\title{
Chris Morris: 'The regulatory environment in which dentists practise has become ever more complex and demanding'
}

Interview by Adrian O'Dowd

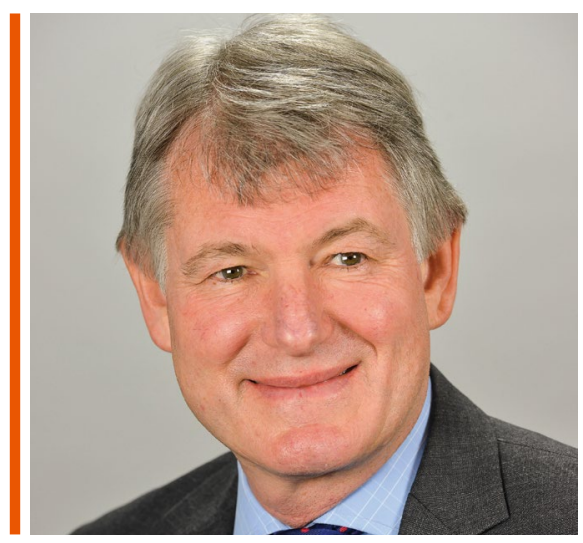

What made you want to be a dentist?

Even at age 17 when I was applying for university, I was torn between dentistry and the law so I applied for both. In my 17-year-old brain, it probably came down to the shortest route to getting professionally qualified. To get to a job with a good income as quickly as possible would allow me to purchase a sports car as soon as possible! I qualified in 1979 from the University of Bristol.

\section{You first practised as a dentist in Bath and then Oxford - what memories do you have of that time?}

In Bath, I worked in a good-quality city centre practice with two great bosses. I was an associate and was doing mainly NHS dentistry. The practice had been known as the place to go to for dentures so I spent a lot of my life relining or replacing sets of dentures that were well beyond their sell-by date.

As a junior member of the practice, I was also asked to see the majority of the practice's emergencies. It was a real baptism of fire in those years. There was no such thing as vocational training back in the early 1980s. You just jumped straight in from dental school.

It opened my eyes to the realities of making a living as an NHS dentist. It was very hard work, stressful, exhausting,
One of the most prominent lawyers for dentists in the UK, Chris Morris recently joined the board of the British Dental Association (BDA) and tells Adrian O'Dowd how he plans to help the trade union navigate an increasingly legally challenging world for the dental profession. frequently rewarding and often frustrating. I was a big fan of the introduction of vocational training when it came in because I think it bridges the gap between dental school and general dental practice.

\section{Tell me about your travelling and where it took you?}

I'd been at the Bath practice for five years and was offered a partnership there. In the same week, a friend of mine said he was going off to travel around India for a year and did I want to join him. I went to India!

I spent a year travelling in India and Nepal and came back overland across Asia and Europe. I decided I needed a change in direction, so I decided to pursue the law option on my return journey.

I found a place doing undergraduate law at Oxford and did some part-time dentistry for a corporate in Oxford.

At the end of that period of study, I was offered a locum associate position in Auckland for a year. I'd always wanted to see New Zealand so the timing was good. New Zealand is just as stunningly beautiful as everyone says, but dentistry there in the 1980s was a very mixed bag. It was essentially private only and I was working in a poor area which meant that we had to turn patients away at reception even though they had abscesses because they didn't have dollars in their pockets.

I found that very hard ethically having come from the NHS where I was used to being able to provide all necessary care for oral health. It made me realise how amazing the NHS was and still is.

What attracted you to switching to legal practice from dentistry?

I had always considered a career in law anyway and travelling had given me a thirst for adventure and change. I was looking for a challenge beyond general dental practice but one where I could still use the dental knowledge and experience I had gained. When I came back from New Zealand, I approached several law firms specialising in healthcare law, and to my delight, I received offers of articles from all of them.

I chose Hempsons because the firm had a great reputation and they were based in the heart of London. Little did I know when I walked in to start my training in 1991 that I would stay for 30 years and spend the last three years as the firm's Senior Partner.

\section{What useful lessons did you learn} during your 30 years at Hempsons?

I enjoyed every aspect of my professional life at 
Hempsons. It was a challenging and stimulating environment working with many great people who really cared about going the extra mile and getting the very best for their clients.

Hempsons is a national healthcare law firm with four offices, roughly 250 staff and 50 partners offering a complete range of legal services to the NHS and many healthcare bodies including the BDA, as well as individual practitioners.

I had the privilege of representing clients before every type of court and tribunal in the land. That includes Magistrates and Crown Courts, County Courts and High Courts. I went before the Court of Appeal, the House of Lords, the Privy Council, Coroner's Inquests, NHS and First Tier tribunal cases and, more than anything else, Professional Conduct Committee and Health Committees of the General Dental Council and also the General Medical Council, the General Optical Council and the Health Professions Council.

I have dealt with a massive range of cases from the most serious - manslaughter/death in dental chair type cases, rape, sexual assault, fraud on the NHS, serious injury to patients - to the more mundane cases of poor clinical practice. No two cases were ever the same.

It's been a wonderful journey. On a personal career level, a large law firm like Hempsons offers a career structure. I progressed rapidly from being a trainee to a qualified solicitor, to a salaried partner and then Equity partnership.

I was on the firm's Management Board for the last six years and was elected the Senior Partner for the last three.

I suspect I'm the only dentist who has ever been the Senior Partner of a law firm in the UK.

\section{Was the majority of your work at Hempsons helping dentists or a range of healthcare practitioners?}

I was a defence solicitor running a team of lawyers defending healthcare practitioners in their professional lives. Around 75\% of my personal clients were dentists or dental bodies/ institutions including the BDA. The rest of my clients were doctors and other healthcare professionals, such as opticians. The largest slice of my work was the GDC and I have become a recognised expert in the field of regulatory law.

\section{Do you think being a dentist has become more challenging over the years (legally speaking)?}

Without doubt, yes. The regulatory environment in which dentists practise has become ever more complex and demanding. The risk of litigation has increased and the prospect of what lawyers call double or triple jeopardy (the same set of facts giving rise to problems in two, three or more jurisdictions) is much higher.

For example, a patient might claim a dentist has assaulted them in some way or touched them inappropriately perhaps whilst they were in the chair. The patient might report the dentist to the police so it starts a criminal investigation, and also report them to the GDC and NHS England and the patient could sue the dentist in a civil court. That has become more commonplace.

Also the GDC has become proactive rather than reactive and goes looking for problems. We have also had the advent of dental claim specialist legal firms as well so you are much more likely to be sued as a dentist now. The need to go to defence lawyers has increased significantly in my time.

\section{Has the profession changed in that time?}

Yes, it has in many ways. The profession has had to react to the changes in the regulatory environment. The vast majority of practitioners have managed that process very successfully. It is easier to do so in larger numbers. I have seen the development of many bigger practices, group practices and corporate dentistry.

In some respects, that's a reaction to the increasing regulatory complexity and the need to comply with it - it's easier to do it with others around to help you.

I think it's a good thing moving in the direction of big practices and corporates because the quality of service for patients is consistent.

The advent of compulsory CPD activity was a game changer because it forced dentists to keep themselves up to date and to go out and meet colleagues when doing that. The BDA has always played an important role in bringing peers together outside the practice environment.

\section{Has the COVID-19 pandemic had a significant impact on dentists in terms of the number of complaints coming from patients?}

I suspect it's too early to know. Claims and litigation can come out of the woodwork for several years afterwards. COVID turned the world upside down and the dental world too. I think dentistry has responded to the challenge in an amazing fashion and I would hope that most patients will understand that dentists did their very best to provide a service in unique and unprecedented circumstances.

\section{What particular skills will you bring to the BDA's Principal Executive Committee (PEC)?}

I have got an unusual combination of wet-fingered dental experience and a wide knowledge of the healthcare world, particularly dentistry, from the legal and the regulatory perspective.

I have also got many years of senior boardlevel management experience running a large business. Hopefully this will allow me to see issues in a novel way and from a different perspective to other PEC colleagues.

\section{Is there anything you are keen to achieve at the BDA?}

The BDA needs to have a louder voice on behalf of the profession on all the topics of the day. Reform of healthcare regulation is underway and the dental profession needs to be heard clearly on its own future. I would like to play a role in that debate and discussion.

The BDA needs to strive to remain relevant and exciting to its membership. It has done a great job offering advice and guidance to members through the turmoil of COVID. That is time-consuming and expensive so the BDA needs to find a way to continue to meet members' needs while ensuring ongoing financial stability.

The BDA has also got to make sure it looks after its great staff members and finds an appropriate balance between home and remote working, like all organisations.

\section{Would you recommend the law as a profession to other dentists?}

I've had a wonderful professional life. I would encourage people to follow their gut instincts in life and to make brave choices. Having said that, the road to qualifying as a solicitor is not short, and finding a place in a law firm as a trainee is now extremely competitive and far from guaranteed.

Working hours as a lawyer are typically very long compared with dentistry, especially if you are ambitious and want to climb the career ladder. So, anyone thinking about this path should do so with their eyes wide open and only after a lot of research. For me, I have never looked back. 